\title{
Desafios na construção de um grupo de gestantes na Unidade de Saúde da Família
}

\author{
Marina Sanches Silvestrini ${ }^{a}$, Maria Luiza Mangino Cardoso ${ }^{b}, B$ runa Rangel Rego ${ }^{c}$ \\ aUniversidade Federal de São Carlos - UFSCar, São Carlos, SP, Brasil \\ 'Programa de Pós-graduação em Terapia Ocupacional, \\ Universidade Federal de São Carlos - UFSCar, São Carlos, SP, Brasil \\ 'Prefeitura Municipal de São Carlos, São Carlos, SP, Brasil
}

\begin{abstract}
Resumo: Este relato descreve uma experiência vivida pelas alunas de graduação em Terapia Ocupacional (bolsistas do Programa de Educação pelo Trabalho - PET Saúde) inseridas em uma Unidade de Saúde da Família da cidade de São Carlos, SP, no processo de planejamento e construção de um grupo de gestantes, juntamente com as famílias e com os profissionais responsáveis pelo acompanhamento pré-natal. O relato descreve a experiência revelando os desafios, a relação com a equipe, bem como a importância dessa na efetividade do grupo. O produto final desse processo foi a criação de um espaço de reflexão, diálogos, trocas e atividades destinadas a essa população que vivencia um período intenso, com angústias, medos e expectativas, necessitando de uma atenção diferenciada, mais específica e integral, que propõe olhar para a gestante em seu contexto geral e não apenas biológico. A fim de demonstrar a importância de espaços como esse, nos fundamentamos nas percepções dos profissionais, nos depoimentos e comportamentos das gestantes e dos familiares participantes. Assim pudemos também observar a transformação na forma de pensar de uma equipe de saúde.
\end{abstract}

Palavras-chaves: Terapia Ocupacional, Gestantes, Recursos Humanos, Territorialidade.

\section{Challenges in forming a group of pregnant women in a Family Health Unit}

\begin{abstract}
This report describes the experience of undergraduate students in Occupational Therapy, who are grantees of the Program of Education through Work - Health (PET - Saúde), inserted in a Family Health Unit in the municipality Sao Carlos, Sao Paulo state, Brazil, in the process of planning and forming a group of pregnant women, their families, and practitioners responsible for the entire process of their prenatal care. The report describes the experience revealing the challenges, the relationship with the team, as well as its importance to the effectiveness of the group. The final product of this process was the creation of a space for reflection, dialogue, exchanges and activities aimed at this population, who experiences an intense period, full of anxieties, fears and expectations. This population deserves more specific, integral and differential attention that proposes to look at these pregnant women not only in their biological contexts, but with an overall view. In order to demonstrate the importance of spaces such as this, we relied on the professionals' perceptions and in the statements and behaviors of the pregnant women and family participants. This way, we could also observe the transformation in the way of thinking of a healthcare team.
\end{abstract}

Keywords: Occupational Therapy, Pregnant Women, Human Resources, Territoriality. 


\section{Introdução}

Para Pichón-Rivière (apud OSÓRIO, 1986, p. 127), um grupo é "um conjunto restrito de pessoas que, ligadas por constantes de tempo e espaço e articuladas por sua mútua representaçáo interna se propóem de forma explícita ou implícita a realização de uma tarefa que constitui sua finalidade". Formar grupos como estratégia de cuidado na atenção básica é uma abordagem atual que se faz necessária na medida em que é parte do cuidado integral proposto pelo Sistema Único de Saúde. Mas mesmo normatizados e definidos como estratégia significativa, ainda falta muito para que os grupos sejam uma realidade efetiva. Vemos com maior frequência práticas e procedimentos individuais e tradicionais do cuidado em saúde em detrimento da ação coletiva e em grupo. Predomina o senso comum: faltam instrumentos e conhecimentos aos profissionais, em virtude de sua formação, para intervençôes em grupos e atividades coletivas. Os profissionais, em sua prática, priorizam, claramente, os atendimentos individuais pautados em procedimentos tradicionais.

Quando se propóem a formar grupos, com maior ênfase os de caráter educativo, valem-se de palestras, metodologias expositivas, em geral destinadas a plateias imensas e que só teriam sucesso sob essa condição (FURLAN; CAMPOS, 2010, p. 106).

Os grupos na atenção primária promovem alguns benefícios, como citam Furlan e Campos (2010): a) podem originar uma melhor comunicação entre usuários e profissionais na medida em que ambos fazem parte de um todo (o grupo) como iguais, sem a hierarquia do serviço imposta de forma tão marcada como em outros procedimentos; e b) propiciam um espaço de atenção e cuidado em um serviço onde é alta a demanda numérica e há escassez de recursos e tempo de trabalho; sendo assim vemos que existe a capacidade de promover a clínica no espaço grupal (o cuidado náo está somente na medicação e no espaço individual). $\mathrm{O}$ fato de unir as pessoas de uma comunidade pode proporcionar o surgimento de redes de suporte e a vantagem de que algumas terão maior abertura para dialogar sobre suas questóes de saúde-doença em um espaço de grupo, onde percebem a existência de diversas problemáticas além das suas e, talvez, semelhante às suas. Essas são algumas das muitas razóes que justificam as iniciativas de trabalhos coletivos.

Os grupos devem ser tão variados quanto a necessidade populacional e podem seguir diversos temas e enfoques, a depender de diferentes aspectos como a demanda, as características dos participantes, o espaço físico:

Podem ser: esclarecedores, de aprendizado, informativos, terapêuticos, de ajuda mútua, geradores de renda, motivacionais, de aprendizado dos conhecimentos culturais locais, analíticos, de autoajuda, de treinamento, desde que propiciem o aumento do grau de autonomia de suas açốes e do autocuidado para melhora da qualidade de vida. (FURLAN; CAMPOS, 2010, p. 112).

Refletindo sobre esses aspectos pode-se compreender a importância de atuar em grupos, principalmente em relação às demandas que exijam uma atençáo especial como, por exemplo, o cuidado às gestantes.

De maneira geral, esses grupos são desenvolvidos com a finalidade de complementar o atendimento realizado nas consultas, melhorar a aderência das mulheres aos hábitos considerados mais adequados, diminuir ansiedades e medos relativos ao período gravídico e puerperal. Os conteúdos abordados nesses grupos incluem as vivências e necessidades da gestante e de seu parceiro relativas ao aleitamento materno e às práticas de contracepção. (HOGA; REBERTE, 2007, p. 560).

Esse trabalho coletivo realizado é demasiado importante por ser uma estratégia de educação para as futuras mães, visto que se torna um momento de troca de experiências e interação, através de um movimento reflexivo e dinâmico, demonstrando que

[...] a técnica de trabalho com grupos promove o fortalecimento das potencialidades individuais $\mathrm{e}$ grupais, a valorização da saúde, a utilização dos recursos disponíveis e o exercício da cidadania. (REBERTE; HOGA, 2005, p. 187).

Tendo em vista as profundas mudanças corporais e emocionais das gestantes, o grupo mostrou-se fundamental para abordar as dúvidas que surgem a todo o momento, bem como promover o entendimento de que novas adaptaçóes seriam importantes na vida de cada mulher. Segundo Baptista, Baptista e Torres (2006),

[...] a gestação é um momento de mudanças fisiológicas, sociais, familiares e psicológicas, podendo assim ser um período em que se observam aumentos de sintomatologias ou mesmo o desenvolvimento de transtornos psiquiátricos. (p. 41). 
Os grupos de atenção a esse segmento populacional são essenciais para o cuidado integral de todas as especificidades do período da gestação.

O desenvolvimento desses grupos objetiva o atendimento das necessidades originárias das próprias gestantes, seus parceiros e demais membros da família que juntos vivenciam um importante evento familiar. (REBERTE; HOGA, 2005, p. 187).

\section{O grupo, a equipe, o território}

O grupo de gestantes de uma Unidade de Saúde da Família do município de São Carlos foi desenvolvido durante seis meses por alunos de graduação em Terapia Ocupacional, Enfermagem e Fisioterapia (além de contar com a participação do médico, terapeuta ocupacional e enfermeira da unidade) como intervenção prática do Programa de Educação pelo Trabalho (PET). Esse é um Programa do Ministério da Saúde, financiado por ele e que visa unir a teoria acadêmica à prática nos serviços de Saúde Pública e proporcionar um contato dos futuros profissionais da saúde, ainda durante a graduação, com a realidade dos serviços, sendo assim uma união dos conteúdos teóricos a uma vivência que marca uma experiência indispensável para a formação dos alunos participantes.

O grupo reunia-se uma vez por semana, na própria unidade, nos dias em que eram agendadas as consultas de pré-natal, com o objetivo de concentrar o maior número de gestantes, visto que as consultas médicas tornaram-se um ponto de partida para tentarmos fortalecer e manter o grupo. Nessa unidade há pouca adesão da comunidade aos grupos realizados, um fator que desmotiva os próprios profissionais a criarem estratégias coletivas na Unidade de Saúde da Família.

O período de duração do grupo não era predeterminado, dependia da atividade proposta e do interesse demonstrado pelas gestantes. A escolha das atividades e temas a serem discutidos acontecia de forma multidisciplinar, assim, antes de cada sessão, os alunos e profissionais debatiam o que seria realizado e quais materiais e recursos seriam necessários. Alguns exemplos de atividades realizadas foram: rodas de conversa e debates sobre as consequências do álcool e outras drogas (principalmente o tabaco) na gestação, a saúde do bebê e outros riscos - coordenadas pelo médico; reflexôes acerca dos temas da amamentação, da hora do parto, e do tipo de parto - coordenadas pelos alunos da enfermagem; vivências práticas de Shantala ${ }^{1}$, reflexôes sobre os sentimentos na gestação, a participação familiar nesse período - coordenadas pelas graduandas em Terapia Ocupacional. Com esse enfoque nas atividades - informativas, reflexivas, vivenciais - o grupo tinha como finalidade um cuidado para além das consultas médicas, levando em consideraçáo a complexidade do período da gestação.

Ao serem incorporados à mulher, os valores do aleitamento materno para a criança, ou seja: garantia da saúde, promoção do bem-estar físico e emocional, sua contribuição na formação, crescimento e desenvolvimento infantil e na resistência do organismo a doenças, acaba-se por instituir à mulher relaçóes de poder sobre o controle do desenvolvimento, morbidade e mortalidade infantil. (NAKANO; MAMEDE, 1999, p. 71).

Na prática grupal todos os participantes (profissionais, alunos e gestantes) organizavam e debatiam em conjunto; tal atividade levava a resultados expressivos, pois o trabalho era realizado pela equipe interdisciplinar, visto que todos dialogavam, compartilhando saberes. Todos se empenharam para que os encontros se tornassem um espaço de promoção de saúde, enfatizando a importância das diversas áreas na composição da equipe.

[...] observa-se que na situação de trabalho coletivo, em que há menor desigualdade entre os diferentes trabalhos e os respectivos agentes, ocorre maior integração na equipe. À medida que o trabalho em equipe é construído, efetivamente, na relação intrínseca entre trabalho e interação, quanto mais próximo o estatuto de sujeito ético-social dos agentes, maiores as possibilidades de eles interagirem em situaçôes livres de coação e de submissão, na busca de consensos acerca da finalidade e do modo de executar o trabalho. (PEDUZZI, 2001, p. 107).

Uma dificuldade importante a ser destacada é a questão do território: nesse bairro, a procura pelos serviços de saúde é realizada predominantemente pela população idosa. Devido a esse fator, os serviços dessa unidade são estruturados para tal populaçáo e para atender as necessidades básicas da comunidade em geral. Foi preciso vencer essas barreiras para que identificássemos demandas ainda não muito exploradas: as gestantes do território. Depois foi primordial termos motivação e criatividade para colocar a ideia de atuar com a populaçáo de gestantes, justificá-la e fazê-la ser aceita pela equipe, para afinal ser posta em prática. 
Esse grupo apresentava uma minoria que aparecia periodicamente nos serviços para consultas mas não era considerada como população-alvo de programas realizados na unidade, ou seja, não tinha ainda um espaço para discutir e refletir, junto aos profissionais da saúde, questóes tanto objetivas como subjetivas relacionadas ao momento que estavam vivendo. Mas acreditava-se que embora fossem uma minoria, todas tinham direito a uma atenção efetiva.

Nesse contexto de desafios e oportunidades foi construído junto à equipe esse espaço coletivo que possibilitou a inserção significativa das gestantes, como também um maior diálogo entre elas e os profissionais da Unidade de Saúde da Família, permitindo a circulaçáo de informaçóes importantes acerca da gestação, que muitas vezes não eram exploradas nos procedimentos usuais como as consultas do pré-natal. O grupo tem a importante tarefa de proporcionar que as trocas de experiências ocorram de forma horizontal, diferentemente do que ocorre em uma consulta ou atendimento no qual fica implícita uma relação hierárquica entre profissional-paciente, o que dificulta a troca de saberes e inibe determinados questionamentos e colocaçôes do usuário do serviço.

Portanto, pode-se fomentar e participar de momentos permeados de dúvidas, desabafos, diálogos e sem preconceitos. A experiência foi gratificante e satisfatória para os participantes e culminou em aprendizagens relevantes.

\section{Relatos}

Abaixo estão alguns relatos dos profissionais e das gestantes que participaram das atividades em grupo; neles encontramos alguns apontamentos sobre essa vivência, as aprendizagens, o trabalhar em equipe, a ação de cuidado e outras questôes:

\section{J. (gestante)}

"Pra mim o grupo foi muito legal, me ajudou a esclarecer muitas dúvidas sobre o parto, com o bebê depois do nascimento, me ajudou na orientação sobre amamentação e outros..."

A. (enfermeira)

"O grupo de gestantes vem com o objetivo de integrar a equipe à comunidade, estabelecendo vinculo entre eles e, principalmente, criando vinculo com a gestantelbebêlcuidador. É muito importante, pois esclarecemos dúvidas e trocamos experiências uma com as outras (participantes) familia-acompanhante/profissionais envolvidos) e aprendemos a aprender como é a realidade de cada individuo. Através desse grupo, conquistamos a máe para uma parceria após o nascimento do bebê, na qual podemos desenvolver um papel cuidador, humanizado, desde a fecundação, gestação, nascimento, puericultura (dias de hoje), até a adolescência, juventude, fase adulta e assim por diante. Criando, com isso, um vínculo fortalecido pelo cuidado do cuidar."

\section{S. (gestante)}

"O grupo foi muito bom para mim, me tirou muitas dúvidas. Eu gostei de todos os assuntos conversados e se tivesse outro grupo eu voltaria!"

B. (terapeuta ocupacional)

\begin{abstract}
"Ando bastante envolvida com a questão do parto humanizado e acredito que essa humanização tem inicio nas atividades de assistência prestadas às gestantes nas unidades de saúde e nas relaçōes estabelecidas nesse contexto. Quando oferecemos informação, desenvolvimento de capacidade crítica (principalmente para lidar com as violências obstétricas), troca de experiências e somamos a isso profissionais acolhedores e alunos empenhados em aprender e que estão ali não para consolidar a hierarquia implícita nas relaçōes entre profissional e paciente mas sim para trocar também, para permitir-se aprender junto, ai sim encontro motivação e vejo resultados relevantes. Acho que esse é o caminho... que há ainda muito para se trilhar, mas que a semente foi plantada. A equipe foi sensibilizada, olhares foram ampliados e agora o espaço mostra-se mais receptivo e acolhedor para essa clientela."
\end{abstract}

\section{Considerações finais}

Conclui-se através dessa experiência inovadora em uma Unidade de Saúde da Família na cidade de São Carlos que existem demandas que são menos frequentes, todavia devem ser exploradas em todos os âmbitos, indo além da abordagem biomédica. Por meio do grupo de gestantes nos defrontamos com os questionamentos e as sensaçóes que surgem durante a gravidez. $\mathrm{O}$ grupo pôde abordar assuntos que muitas vezes não são explicitados por falta de oportunidade, percepção ou até mesmo por conta do constrangimento das gestantes em relação ao médico; mas ao se perceberem em um espaço onde as dúvidas e outras questóes podiam ser compartilhadas, as gestantes se sentiram mais confortáveis. Uma grande conquista foi uma maior sensibilização da equipe, permitindo um olhar mais ampliado e acolhedor para toda a comunidade. Vínculos foram formados, experiências trocadas, dúvidas sanadas e 
sementes de um tratamento mais humanizado foram plantadas. E os frutos que foram (e serão) colhidos podem melhorar a vida de muitos usuários da saúde pública do município de São Carlos.

\section{Referências}

BAPTISTA, M. N.; BAPTISTA, A. S. D.; TORRES, E. C. R. Associação entre suporte social, depressão e ansiedade em gestantes. Revista de Psicologia da Vetor Editora, Cubatão, v. 7, n. 1, p. 39-48, 2006.

FURLAN, P. G.; CAMPOS, G. W. S. Os grupos na Atenção Básica à Saúde. Brasília: Ministério da Saúde, 2010. p. 106-116. (Caderno Humaniza SUS: Atenção Básica, v. 2).

HOGA, L. A. K.; REBERTE, L. M. Pesquisa-ação como estratégia para desenvolver grupo de gestantes: a percepção dos participantes. Revista da Escola de Enfermagem da USP, São Paulo, v. 41, n. 4, p. 559-566, 2007.
NAKANO, A. M. S.; MAMEDE, M. V. A prática do aleitamento materno em um grupo de mulheres brasileiras: movimento de acomodação e resistência. Revista Latino-Americana de Enfermagem, Ribeirão Preto, v. 7, n. 3, p. 69-76, 1999.

OSÓRIO, L. C. Grupoterapia hoje. 2. ed. Porto Alegre: Artes Médicas, 1986.

PEDUZZI, M. Equipe multiprofissional de saúde: conceito e tipologia. Revista de Saúde Pública, São Paulo, v. 35, n. 1, p. 103-109, 2001. http://dx.doi.org/10.1590/ S0034-89102001000100016

REBERTE, L. M.; HOGA, L. A. K. O desenvolvimento de um grupo com gestantes com a utilização da abordagem corporal. Revista Texto \& Contexto Enfermagem, Florianópolis, v. 14, n. 2, p. 186-92, 2005.

VICTOR, J. F.; MOREIRA, T. M. M. Integrando a família no cuidado de seus bebês: ensinando a aplicação da massagem Shantala. Acta Scientiarum. Health Science, Maringá, v. 26, n. 1, p. 35-39, 2004.

\section{Contribuição dos Autores}

Marina Sanches Silvestrini e Maria Luiza Mangino Cardoso foram responsáveis pela concepção e redação do texto e Bruna Rangel Rego colaborou com a redação do texto.

\section{Notas}

1 A Shantala é uma massagem que se originou na Índia, transmitida de geração em geração. A massagem estimula vários pontos cutâneos do bebê, influenciando positivamente seu corpo e mente, além de promover uma importante interação com a mãe. (VICTOR; MOREIRA, 2004, p. 36). 